\title{
PREDICTION OF HAUGH UNIT THROUGH ALBUMEN HEIGHT AND EGG WEIGHT
}

\author{
Rafea M. T. khaleel \\ Animal Production Dept./ College of Agriculture and Forestry /University of \\ Mosul /Iraq \\ Email:rafhtaher2017@gmail.com
}

\begin{abstract}
Haugh unit which introduced by Raymond Haugh in 1937 is the most scale used to measure the egg quality by equation $(\mathrm{HU}=100 * \log (\mathrm{h}+7.57)-(1.7 * \mathrm{~W} 0.37)$. The aim of this research is to construct a Haugh unit prediction equation through albumen height and egg weight .1503101 value of Haugh unit were calculated using Microsoft Excel spreadsheet functions. The data of egg weight ranged from 40 to 65 gm by increment (0.01) gm, and albumen height from 4 to $10 \mathrm{~mm}$ by increment $(0.01) \mathrm{mm}$. The results indicates that there was a significant positive correlation between Haugh unit and albumen height (0.969) and negative correlation between Haugh unit and egg weight (-0.215), and the analysis of variance results for regression showed that the mean square of the model including these two variables were highly significant $(\mathrm{P} \leq 0.0001)$ with coefficient of determination R2 (0.985) which indicate that the prediction equation $(\mathrm{HU}=58.235-0.334 \mathrm{~W}+6.256 \mathrm{~A})$ can predict Haugh unit with high accuracy which was confirmed by a residual analysis test.
\end{abstract}

Keywords: Albumen height, Egg weight, Haugh unit, Prediction

Received: 21/10/2019 Accepted: 1/12/2019

\section{INTRODUCTION}

An eggs is important in the human diet because it is inexpensive, nutritious food and its quality directly relates to human health (Aboonajmi and Najafabadi, 2012) The chicken egg is one of the finest foods, offering human an almost complete balance of essential nutrients with proteins, vitamins, minerals and fatty acids of great biological value (De Menezes et al,2012). Egg quality has been defined as its characteristics that affect its acceptability to the consumers. Yimenu et al (2017) indicate that the modern poultry industry is interested in evaluating alternative methods that can be used to measure quality parameters more quickly, and among the main quality parameters of interest is Haugh unit. Haugh unit introduced by Raymond Haugh at 1937 which is calculated by the equation $=100 * \log (\mathrm{h}+7.57)$ $\left(1.7^{*} \mathrm{w} 0.37\right)$ (Morina et al,2015) where $\mathrm{h}$ represents albumen height, $\mathrm{W}$ is the egg weight . Sekeroglu and Altuntas (2008) pointed out that the height of albumen increases as the weight of eggs increases. Scott and Silversides (2000) found that the strain of layer affects albumen quality. Dikmen et al (2017), Yilidrim and Kaya (2017) found that egg quality affected by the housing system and layer age. Curtis et al (2005) also stated that egg quality affected by layer age. Adeolu and Okoleh (2011) stated that egg weight had a positive correlation with all internal egg traits except Haugh unit. Ahmadi and Rahimi(2011) indicated that internal egg quality may be affected by several factors such as hen strain, storage, age, induced molt, 
nutrition, and disease, and understanding these factors help in the production of high-quality eggs. Duman et al (2016) studied the correlation between shape index and egg quality traits and he found a significant positive correlation with Haugh unit and albumen index but not significant on yolk index, yolk color, albumen $\mathrm{pH}$, yolk and Albumen blood spot. Ukwu et al (2017) studied the effect of egg weight on egg quality traits, he did not find a significant effect of egg weight on Haugh unit. Onunkwo and Okoro(2015) In a study to develop a prediction equation for the egg internal quality traits from egg weight did not found a significant regression of albumen height and Haugh unit from egg weight where the equations in three varieties of Guinea fowls as follows: hu=83.831+0.127 $\mathrm{x}+0.296$ ( black), $h u=108.612-0.507 x+0.214$ (lavender), hu=89.633-0.018x +0.188 (pearl) where $X=$ egg weight.

The aim of the present study is to construct a reliable regression equation to predict the Haugh unit through weight of eggs and albumen height and to estimate correlation coefficients between these three variables.

\section{MATERIALS AND METHODS}

This study was conducted on Haugh unit data, where 1503101 value of Haugh unit was calculated using the following equation which introduced by raymond Haugh in 1937:

$\mathrm{HU}=100 * \log (\mathrm{H}+7.57)-\left(1.7 * \mathrm{~W}^{0.37}\right)$

where $\mathrm{HU}=$ Haugh unit, $\mathrm{H}=$ Albumen height in $\mathrm{mm}, \mathrm{W}=$ Egg wight in gm .These Haugh unit values calculated from 601 value of Albumen height ranged between $(6$ -10) $\mathrm{mm}$ with 0.01 increment (ie $4.00,4.01,4.02,4.03,4.04$ and 2501 value of egg weight ranged between $(40-65)$ gm with 0.01 increment (ie 40.00, 40.01, 40.02, 40.03, 65 ), and the overlap of these two sets of values produced 1503101 value of Haugh unit, where each value of albumen height were taken with all values of egg weight, where these number of Haugh unit values obtained by helpful of Microsoft Excel spreadsheet functions especially auto fill function.

The three sets of values (Haugh unit, Albumen height, egg weight) entered in Anonymous 2007 program in three columns to find the relationship between them, especially correlation coefficient, and regression equation of Haugh unit as dependent variable, albumen height and egg weight as independent variables through different methods, and the following best regression equation which represent the relationship between them was obtained: (Al-Rawi, 1987)

Haugh unit $=58.235-0.334 \mathrm{~W}+6.256 \mathrm{H}$

which was confirmed by a residual analysis test.

\section{RESULT AND DISCUSION}

The values of simple linear correlation coefficients between egg weight, albumen height, and Haugh unit is shown in table (1), there is a significant negative correlation coefficient $(\mathrm{P} \leq 0.01)$ between the egg weight and Haugh unit $(-0.215)$ and a significant positive correlation coefficient between the albumen height and Haugh unit ( 0.969) While there was no correlation between the egg weight and the albumen height (0), and from previous studies, Sinha et al (2018) found high 
correlation between Haugh unit and albumen height (0.934), Hou and Yang (2005) found a significant correlation between albumen height and Haugh unit (0.98), while (sekeroglu and altuntas 2009) did not found a significant correlation between egg weight and Haugh unit, Rathert et al(2011) found a significant correlation between egg weight and albumen height $(0.60)$, (Shi et al, 2009) found that correlation coefficient between egg weight and albumen height was (0.092) and with Haugh unit (-0.139), Kul and Seker (2004) found a significant correlation $(0.41)$ between egg weight and albumen height, and non significant correlation between egg weight and Haugh unit (0.11) in quail eggs.

Table(1): Correlation coefficient between, egg weight, albumen height. Haugh unit.

\begin{tabular}{|c|c|c|c|}
\hline & Egg weight & Albumen height & Haugh unit \\
\hline Egg weight & 1 & 0 & $-0.215^{* *}$ \\
\hline Albumen height & 0 & 1 & $0.969^{* *}$ \\
\hline Haugh unit & $-0.215^{* *}$ & $0.969^{* *}$ & 1 \\
\hline
\end{tabular}

$* *$ correlation is significant $(\mathrm{P}<0.01)$

Table (2): Results of the variance analysis of the regression, and it is noted that the mean square of regression, which include the two independent variables (egg weight and albumen height) were highly significant $(\mathrm{P} \leq 0.000)$.

Table (2): ANOVA table of regression model.

\begin{tabular}{|c|c|c|c|c|c|}
\hline MODEL & Sum of squares & Df & Mean squares & F & Sig \\
\hline Regression & 185791093.000 & 2 & 92895546.520 & 48291170.960 & 0.00 \\
\hline Residual & 2891439.874 & 1503097 & 1.924 & & \\
\hline Total & 188682532.900 & 1503099 & & & \\
\hline
\end{tabular}

The coefficients of regression model include constant (58.235), egg weight $\mathrm{W}$ (-0.334), albumen height $\mathrm{H}$ (6.256), where all these coefficients show high significant effects (0.000), so the regression model to predict Haugh unit value from egg weight and albumen height is:

Haugh unit $=58.235-0.334 \mathrm{~W}+6.256 \mathrm{H}$.

To examine the accuracy of regression model can be judged by verifying the hypothesis of normal distribution of errors and homogenization of its variance where it is noted from table (3) that the mean of residual and standard predicted value and standard residual equal to zero.

Table (3): Residuals statistica.

\begin{tabular}{|c|c|c|c|c|}
\hline & Minimum & maximum & Mean & Std.deviation \\
\hline Predicted value & 61.2544 & 105.9206 & 84.1335 & 11.42564 \\
\hline Residual & -5.57437 & 1.69474 & 0.0000 & 1.42819 \\
\hline Std. predicted value & -2.002 & 1.907 & 0.000 & 1.000 \\
\hline Std. residual & -3.902 & 1.186 & 0.000 & 1.000 \\
\hline
\end{tabular}

The residual of regression should follow a normal distribution where the residuals are the differences between the observed value and the predicted value, and in order to examine the normal distribution of residuals, were we can see the 
normal p- p plot of regression as figure (1) shows that most of values located within the normal distribution curve, and from figure (2) noted that residuals are close to regression line and distributed normally and it takes the shape of crescent and its variance increased or decreased and not constant.

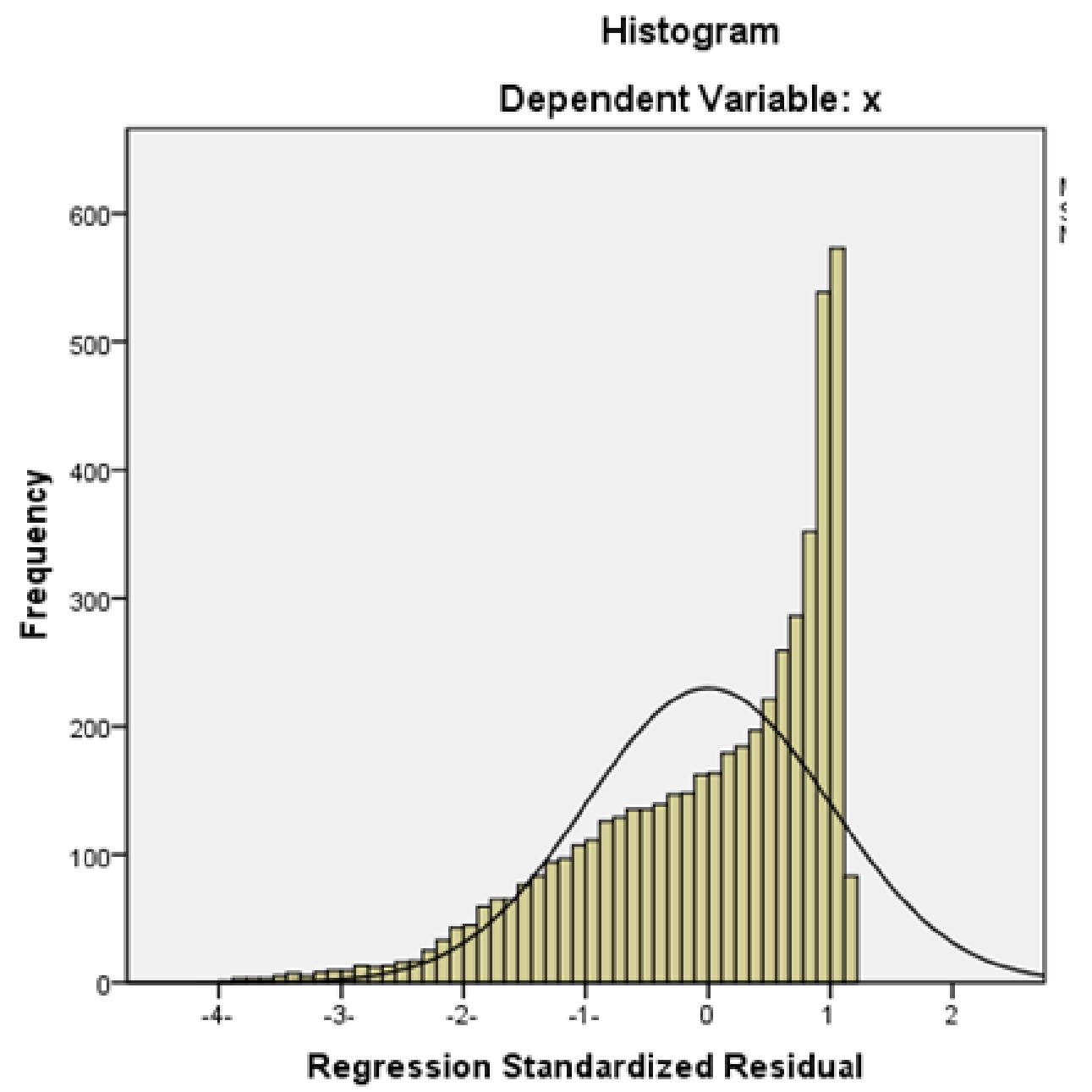

Figure(1): Normal distribution of residuals

Table (4) show a sample of calculated and predicted Haugh unit for different values of egg weight and albumen height ranged from (40-65) gm and (4-10) $\mathrm{mm}$ respectively, it is clear that predicted value are close to calculated values where the average of this differences was (-0.29) and the largest difference was (-5.025). 
Normal P.P Plot of Regression Standardized Residual

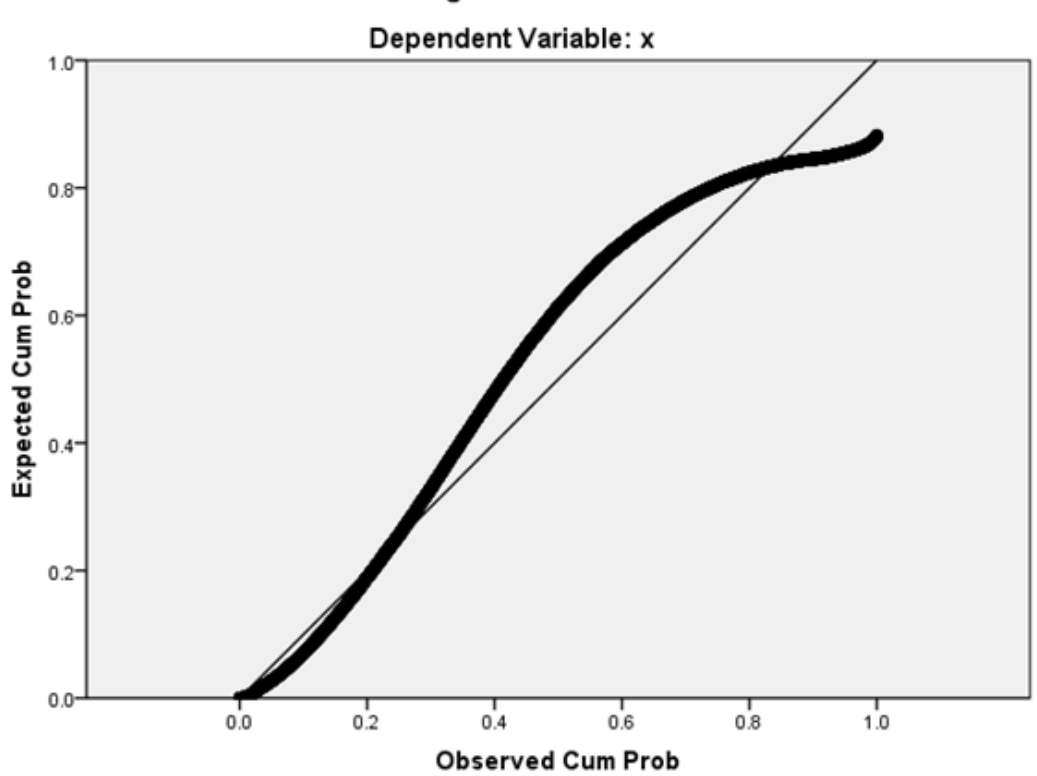

Figure(2): Normal P-P plot of regression standardized residual

Table(4): Calculated and predicted value of hugh unit*

\begin{tabular}{|c|c|c|c|c|}
\hline EW(gm) & AH(mm) & HU calculated & HU predicted & Difference \\
\hline 40 & 4 & 69.14 & 69.899 & -0.759 \\
\hline 41 & 5 & 76.74 & 75.821 & 0.919 \\
\hline 42 & 6 & 83.20 & 81.743 & 1.457 \\
\hline 43 & 7 & 88.84 & 87.665 & 1.175 \\
\hline 44 & 8 & 93.83 & 93.587 & 0.243 \\
\hline 45 & 9 & 98.31 & 99.509 & -1.199 \\
\hline 46 & 10 & 102.37 & 105.431 & -3.061 \\
\hline 47 & 4 & 65.37 & 67.561 & -2.191 \\
\hline 48 & 5 & 73.64 & 73.483 & 0.157 \\
\hline 49 & 6 & 80.58 & 79.405 & 1.175 \\
\hline 50 & 7 & 86.58 & 85.327 & 1.253 \\
\hline 51 & 8 & 91.85 & 91.249 & 0.601 \\
\hline 52 & 9 & 96.55 & 97.171 & -0.621 \\
\hline 53 & 10 & 100.79 & 103.093 & -2.303 \\
\hline 54 & 4 & 61.62 & 65.223 & -3.603 \\
\hline 55 & 5 & 70.60 & 71.145 & -0.545 \\
\hline 56 & 6 & 78.04 & 77.067 & 0.973 \\
\hline 57 & 7 & 84.40 & 82.989 & 1.411 \\
\hline 58 & 8 & 89.94 & 88.911 & 1.029 \\
\hline 59 & 9 & 94.86 & 94.833 & 0.027 \\
\hline 60 & 10 & 99.28 & 100.755 & -1.475 \\
\hline 61 & 4 & 57.86 & 62.885 & -5.025 \\
\hline 62 & 5 & 67.60 & 68.807 & -1.207 \\
\hline 63 & 6 & 75.56 & 74.729 & 0.831 \\
\hline 64 & 7 & 82.28 & 80.651 & 1.629 \\
\hline 65 & 8 & 88.11 & 86.573 & 1.537 \\
\hline
\end{tabular}

$\mathrm{EW}=$ Egg weight(gm), AH= Albumen height(mm), HU = Haugh unit 
The $(R)$ value of this model is (0.992), and $R^{2}$, adjusted $R^{2}$ is $(0.985)$ which mean that regression model can predict Haugh unit value with high accuracy $(98.5 \%)$.

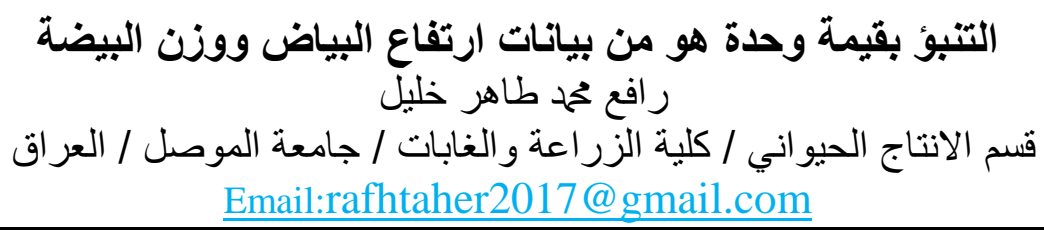

تعتبر وحدة هو( Haugh ) التي وضعت من قبل Raymond Haugh عام 1937 من أهم المقاييس

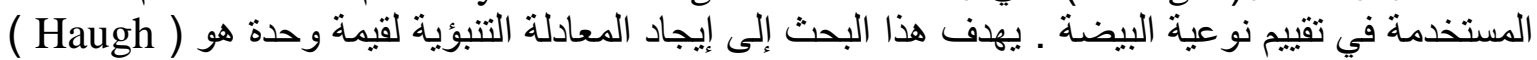

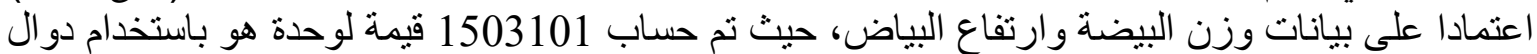

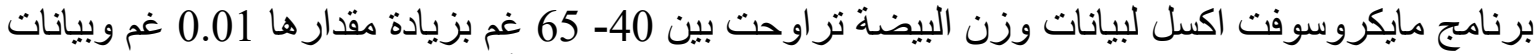

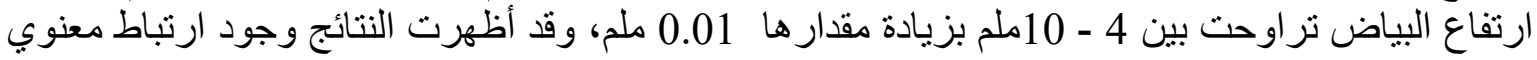

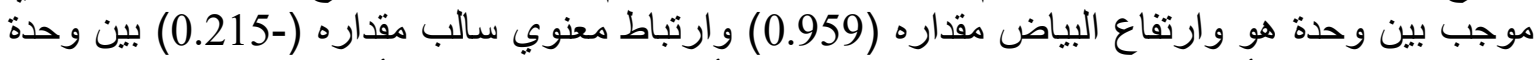

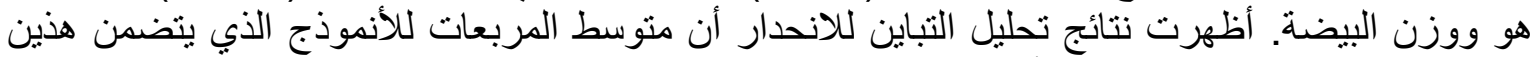

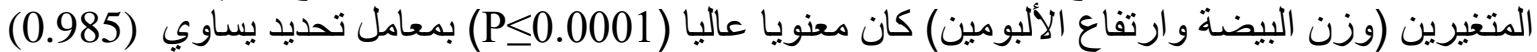

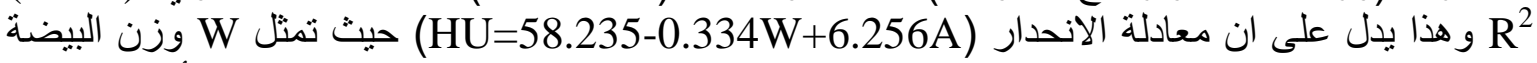

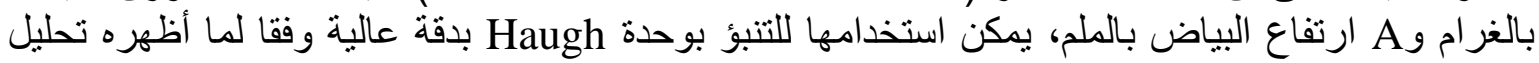

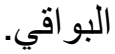

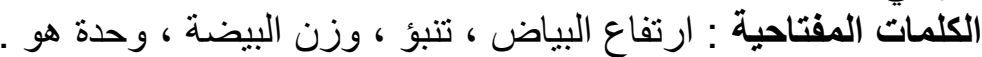

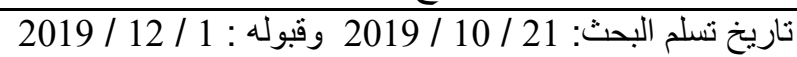

\section{REFERENCES}

Aboonajmi,M; and T.A. Najafabadi.(2012).Quality assessment poultry egg using spectroscopy and maximum likelihood(ML) classifier .NABECCSBE/SCGAB2012joint meeting and technical conference .Northeast agricultural \&biological engineering conference.Canadian society of bioengineering.Leakhead university, Orillia,Ontario,July 15-18 2012.

Adeolu,A.I; and V.U.Oleforuh-Okoleh(2011).Phenotpic relations between egg weight and other egg quality traits of south eastern Nigeria local chicken.Nigerian Journal of Animal production .38:3-8.

Ahmadi,F;and F.Rahimi(2011).Factors affecting quality and quantity of egg production in laying hens:Areview.World applied Sciences journal. 12:3:372-384.

Al-Rawi,K.M.(1987).Introduction to regression analysis .Directorate of Dar AlKutub for printing and publishing, Mosul University, 576.

Anonymous (2007). Statistical Package for Social Sciences. SPSS Inc. 16.0 for windows.

Curtis,P.A;L.K.Kerth; and K.E.Anderson(2005).Quality and compositional characteristics of layer hens as affected by bird age.XI European symposium on the quality of eggs and egg products.Doorweth.The Netherlands.23-26 May2005. P:214-219.

De Menezes,P.C;E.R.De Lima;J.P.De Medeiros;W.N.K.De Olivera;J.EvencioNeto(2012).Egg quality of laying hens in different conditions of storage 
,ages and housing densities.Revista Brasileira de Zootecnia .41:9:20642069.

Dikmen.Y;A.Ipek;U.Sahan;A.Sozcu;S.baycan(2017).Impact of different housing systems and age of layers on egg quality characteristics.Turkish journal of veterinary Animal Science.41:77-84.

Duman.M;A.Sekeroglu;A.Yildirim;H.Eleroglu;and O.Camci(2016).Relation between egg shape index and quality characteristics.Europian poultry science .80:1-9.

Hou.Z; and N.Yang(2005).Hertabilities and genetic and phenotypic correlation of egg quality traits in brown-egg dwarf layers. Poultry Science.84:12091213.

Kul.S; and I.Seker(2004).Phenotypic correlations between some external and internal egg quality traits in the japanese quail(Coturnix coturnix japonica).International journal of poultry science.3:6:400-405.

Monira, K. N., Salahuddin, M., \& Miah, G. (2003). Effect of breed and holding period on egg quality characteristics of chicken. International Journal of Poultry Science, 2:4: 261-263.

Onunkwo.D.N; and I.C.Okoro(2015).Predicting egg quality and egg production traits using egg weight and body weight respectively in three varieties of helmeted guinea fowls in humid tropics.International journal of livestock research 5:3:111-121.

Rathert, T.C;F. Uckardes; D.Narinc; T. Aksoy (2011). comparison of principal component regression with the least square method in prediction of internal egg quality characteristics in japenese quails.Kafkas University Veterinary Fak.Derg. 17:5:687-692.

Rath.P.K;P.K.Mirsha;B.K.Mallick;and N.C.Behura(2015).Evaluation of different egg quality traits and it interpretation of their mode of inheritance in white leghorns.Vetetrinary world.8:3:449-452.

Scot.T.A ; and F.G.silversides(2000).The effect of storage and strain of hen on egg quality.Poultry Science.79:1725-1729.

Şekeroğlu, A., \& Altuntaş, E. (2009). Effects of egg weight on egg quality characteristics. Journal of the Science of Food and Agriculture, 89(3), 379383.

Shi.S.R;K.H.Wang;T.C.Dou;and H.M.Yang(2009).Journal of food Agriculture \& enviroment.7:2:432-434.

Sinha.B;K.G. Mandal; R.K. Singh; R.Kumari; and P.Kumar (2018). Phenotypic correlation among egg quality traits- A Review. International Journal of pure and applied bioscience.5:3:293-300.

Ukwu.H.O;C.O.Ezihe;S.K.Asaa;and M.E.Anyogo.(2017). Effect of egg weight on external and internal egg quality traits of Isa brown egg layer chickens in Nigeria.Journal of animal science and veterinary medicine.2:126-132.

Yimenu.S.M;J.Y.kim.and B.S.Kim(2017).Prediction of egg freshness during storage using electronic nose .Poultry Science 96:3733-3746.

Yildirim.h; and S.Kaya(2017).Egg production and quality traits of layers kept in free range housing system .greener Journal of Agriculture sciences. 7:2:6064. 